\title{
Seed Germination of Rigid Ryegrass (Lolium rigidum) and Sterile Oat (Avena sterilis) under Water Salinity Conditions at Constant or Alternating Temperatures
}

\author{
Khalid S. Alshallash ${ }^{(1,2)}$ \\ (1) Chemistry and Biology Department College of Sciences, Shaqra University, Riyadh, \\ Saudi Arabia and ${ }^{(2)}$ Academic visitor, School of Biological Sciences, University of \\ Reading, UK.
}

\begin{abstract}
D IGID ryegrass (Lolium rigidum) and sterile oat (Avena sterilis) are well known grasses in many parts of the world. They grow in both grasslands and arable habitats and both are recorded as serious weeds of arable lands in many countries worldwide. Seed germination of both species was tested against four levels of water salinity $(0,100,300,500 \mathrm{mM} / \mathrm{L}$ of $\mathrm{NaCl})$ and five different temperature regimes, constant at $8^{\circ} \mathrm{C}$ or alternating temperatures at $6 / 14$, $8 / 16,10 / 18$ and $10 / 20^{\circ} \mathrm{C}$, all in dark/light photoperiods of $8 / 16 \mathrm{~h}$, respectively. A. sterilis seeds generally showed higher germination rates than $L$. rigidum in all tested temperature regimes. Germination was very high in both species at alternating $10 / 20^{\circ} \mathrm{C}$, and in $A$. sterilis also at $10 / 18^{\circ} \mathrm{C}$, with nearly $40 \%$ in both. A. sterilis seeds also showed higher germination than $L$. rigidum at a constant temperature of $8^{\circ} \mathrm{C}$, the latter favoring alternating temperatures. A. sterilis seeds resisted water salinity as high as $100 \mathrm{mM} / \mathrm{L}$ of $\mathrm{NaCl}$ and germinated at about $25 \%$, compared to L. rigidum seed, which, while also showing some resistance to $100 \mathrm{mM} / \mathrm{L}$ of $\mathrm{NaCl}$ only germinated at a rate of about $20 \%$. Both species gave poor germination at higher levels of water salinity of 300 and $500 \mathrm{mM} / \mathrm{L}$ of $\mathrm{NaCl}$. Results confirmed that germination of seeds of both species favoured moderate alternating temperatures and showed some resistance to water salinity, which may indicate how both species can invade and persist in arable lands especially in Mediterranean climates and subtropics conditions.
\end{abstract}

Keywords: Germination, Temperature, Water salinity, Avena sterilis, Lolium rigidum.

\section{Introduction}

Avena sterilis L (Sterile oat) is one the most widespread, common and harmful to arable crop weed species of Mediterranean climates (Damanakis, 1983 and Castellanos-Frias, 2014). It is also widespread across the whole of Europe (Tutin et al., 1980), India (Balyn et al., 1991), North America (Carlson \& Hill, 1985) and Australia (Torner et al., 1984). Chaudhary (1989) confirmed the presence of this species as a serious weed of cereals in Saudi Arabia. Lolium rigidum Gaudin (Annual ryegrass) is also considered a major weed in Mediterranean climatic regions worldwide (Monaghan, 1980; Gracia Baudin, 1982; Jauzein \& Montegut, 1983 and Recasens et al., 1997). Chaudhary (1989) confirmed that L. rigidum is the most serious narrow-leaf weed in cereal fields in Saudi Arabia. It has been also recorded in a check list of weed flora in Saudi Arabia (Elghazali \& Alsoqeer, 2013). Germination is a crucial stage in the life cycle of the plant (Khan \& Gulzar, 2003). Temperature affects the percentage and rate of germination, a crucial stage in the plant life cycle, through its effect on seed deterioration, loss of dormancy and the germination process itself (Roberts, 1988), moreover, temperature fluctuations can stimulate seed germination (Thompson \& Grime, 1983). Temperature, light, water and salinity are all thought to interact at the soil-atmosphere interface to regulate seed germination (Xue et al., 2012), but soil temperature and salinity are the most important factors controlling germination in the saline soils of arid and semi-arid regions (Khan \& Unger, 1999). Salinity generally causes a reduction in germination rates and delays germination and it is both in soil or water a major stress factor limiting seed germination (Shannon, 1998 and Ozdener \& Kutbay, 2008). This paper investigates the effect of constant and fluctuating temperatures and a range of salinity concentrations on seed germination on two very well-known and destructive grass weed species, Avena sativa and Lolium rigidum. Since germination determines abundance, understanding the biological factors which affect it could contribute to both the prediction and control of expected populations.

Corresponding author's email: kalshallash@su.edu.sa

Edited by: Prof. Dr. T. Galal, Faculty of Science, Helwan University, Cairo, Egypt.

DOI: $10.21608 /$ ejbo.2018.3540.1168

(C)2018 National Information and Documentation Centre (NIDOC) 


\section{Materials and Methods}

Seeds of sterile oat (Avena sterilis) and Annual ryegrass (Lolium rigidum) were collected in the late spring of 2014 from a wheat farm in the Aljouf Area of northern Saudi Arabia. Seeds were kept in sealed glass jars and refrigerated at $4^{\circ} \mathrm{C}$ to maintain viability. Experiments were carried out in five incubators maintained at the five temperature regimes under investigation (Fig. 1). Temperatures were: Constant at $8^{\circ} \mathrm{C}$ and alternating at $8 / 16,10 / 18,6 / 14$ and $10 / 20^{\circ} \mathrm{C}$. The lower temperature period lasted $8 \mathrm{~h}$ and seeds were kept in the dark, the higher lasted $16 \mathrm{~h}$ during which seeds were in the light. The same photo period regime $(8 / 16 \mathrm{~h} \mathrm{dark} /$ light $)$ was also applied to the constant temperature regime. Salt solution was prepared at four concentrations: 0 , $100,300,500 \mathrm{mM} / \mathrm{L} \mathrm{NaCl}$ ). Seeds were placed in a double layers of filter paper in sterilized petri dishes, with 20 seeds/petri dish. $10 \mathrm{ml}$ of $\mathrm{GA}_{3}$ solution at 200ppm was added to the seeds of both species at the beginning of the experiment to stimulate germination and break seed dormancy where it existed. Samples were monitored daily for 60 days to maintain moisture levels and to record germination. The experiment followed a block randomized design with four replicates of each treatment. Total germination was analyzed using GenStat (GENSTAT Version 18, VSN International, Hemel Hempstead, UK), germination responses to temperature and salinity were assessed with an ANOVA. Means were compared post hoc by a least significant difference (LSD) multiple comparison test.



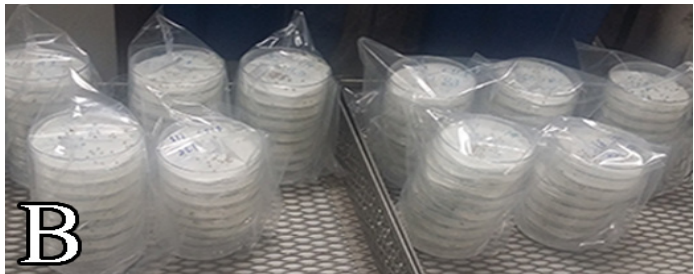

Fig. 1. Germination test procedure where (A) Seeds dispersal within petri dishes, (B) Allocation of petri dishes in the incubators.

\section{Results}

Results are based upon the total number, cumulatively, of germinated seeds at the end of the trial period.

\section{Overall germination by species}

Across all trial conditions combined, significantly higher $(\mathrm{P} \leq 001)$ percentages of $A$. sterilis seeds germinated than of $L$. rigidum, as shown in Fig. 2 , suggesting a better response from $A$. sterilis to the various factors under investigation. However, overall, germination in both species was low, likely because of an absence of response to some water salinity concentrations and some temperatures regimes under investigation, in both species.

\section{Effect of temperatures on seeds germination}

A. sterilis showed higher germination at all temperatures compared to L. rigidum, with maximum germination at alternating temperatures of $10 / 18^{\circ} \mathrm{C}$ and $10 / 20^{\circ} \mathrm{C}$ of about $40 \%$. L. rigidum showed its highest germination at $10 / 20^{\circ} \mathrm{C}$ but only at about $25 \%$ and this was the only germination rate above that achieved at constant $8^{\circ} \mathrm{C}$. Both species favoured higher temperatures, of $10 / 20^{\circ} \mathrm{C}$, for germination, with lower and not significantly different responses at $8,6 / 14$ and $8 / 18^{\circ} \mathrm{C}$. Both species showed higher germination at constant $8^{\circ} \mathrm{C}$ than at $8 / 18^{\circ} \mathrm{C}$. Figure 3 shows germination responses of both species to the different temperatures tested.

\section{Effect of water salinity on seed germination}

Water salinity inhibited germination of both species significantly, even at the lowest tested $\mathrm{NaCl}$ concentration of $100 \mathrm{mM} / \mathrm{L}$. Germination at $100 \mathrm{mM} / \mathrm{L} \mathrm{NaCl}$ was low, but neither species germinated at 300 or $500 \mathrm{mM} / \mathrm{L}$. Figure 4 illustrates the germination responses of both species at different concentrations of water salinity, approximately $20 \%$ of $L$. rigidum seeds germinated at $100 \mathrm{mM} / \mathrm{L}$ of $\mathrm{NaCl}$, compared to $25 \%$ of $A$. sterilis and in the control $(\mathrm{NaCl}$ absent) approx. $30 \%$ of L. rigidum germinated compared to $100 \%$ of $A$. sterilis. 


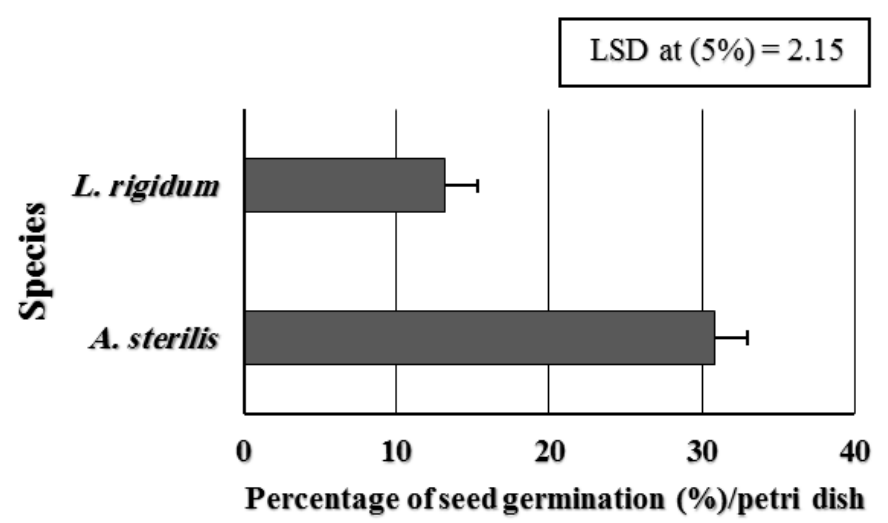

Fig. 2. Overall seed germination responses (\%) of the two tested species. LSD: Least significant difference at $5 \%$.

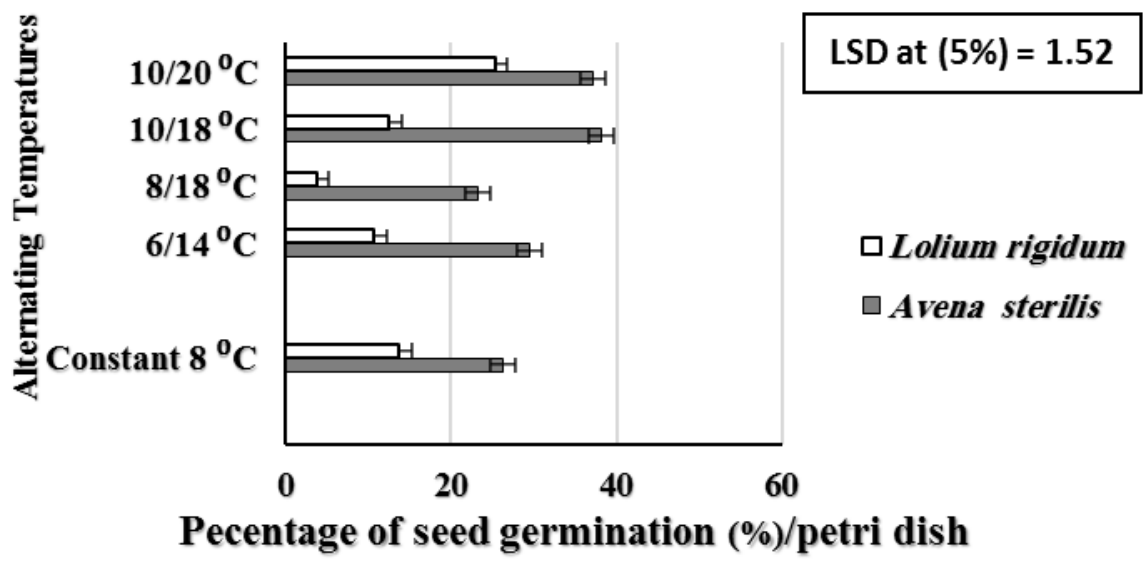

Fig. 3. Seed germination responses of the two species to different temperatures. LSD: Least significant difference at $5 \%$.

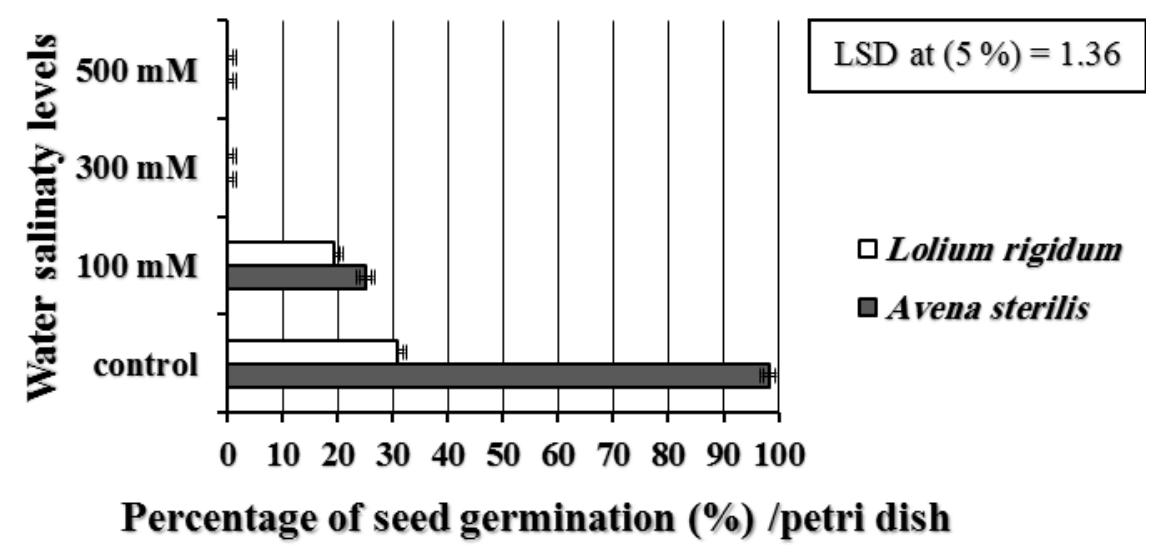

Fig. 4. Germination responses of the two species to different water salinity levels. LSD: Least significant difference at $5 \%$.

Effect of interactions between temperature and water salinity on seed germination

Statistical analysis showed limited interaction between temperature and salinity. However, while salt reduced germination significantly in both species at all temperatures, compared to no salt,
A. sterilis showed moderate germination with $100 \mathrm{mM} / \mathrm{L}$ of salt at both higher temperatures of $10 / 18$ and $10 / 20^{\circ} \mathrm{C}$, and L. rigidum also responded, even with $100 \mathrm{mM} / \mathrm{L} \mathrm{NaCl}$, at $10 / 20^{\circ} \mathrm{C}$. Table 1 shows the percentage of germination at each temperature/salinity interaction. 
TABLE 1. Effect of interaction between temperature and water salinity level on the mean percentage (\%) of germinated seeds of $A$. sterilis and $L$. rigidum/petri dish.

\begin{tabular}{|c|c|c|c|c|}
\hline \multirow{3}{*}{$\begin{array}{l}\text { Temperature Regimes } \\
\left({ }^{\circ} \mathrm{C} \text { for } 8 / 16 \mathrm{~h} \text { dark/light periods) }\right.\end{array}$} & \multirow{2}{*}{\multicolumn{2}{|c|}{$\begin{array}{c}\text { A. sterilis } \\
\text { Water salinity } \\
(\mathrm{mM} / \mathrm{L} \mathrm{NaCl})\end{array}$}} & \multirow{2}{*}{\multicolumn{2}{|c|}{$\begin{array}{c}\text { L. rigidum } \\
\text { Water salinity } \\
(\mathrm{mM} / \mathrm{L} \mathrm{NaCl})\end{array}$}} \\
\hline & & & & \\
\hline & 0 & 100 & 0 & 100 \\
\hline 8 & 20.00 & 1.00 & 6.00 & 5.00 \\
\hline $6 / 14$ & 20.00 & 3.50 & 5.75 & 2.75 \\
\hline $8 / 16$ & 18.25 & 0.25 & 2.50 & 0.00 \\
\hline $10 / 18$ & 20.00 & 10.50 & 5.00 & 4.25 \\
\hline $10 / 20$ & 20.00 & 9.75 & 11.50 & 7.25 \\
\hline
\end{tabular}

LSD: Least significant difference at 5\%(0.05) 3.04

\section{Discussion}

Higher germination occurred in Avena sterilis than Lolium rigidum, although both seed samples were collected simultaneously from the same location and kept in the same storage conditions. Variation in germination, under the experimental conditions, can, therefore, be attributed to natural variation between the two species in seed structure and dormancy characteristics. Both species germinated at all the experimental temperatures, demonstrating their ability to germinate in a wide range of natural climatic conditions. However, alternating temperatures appeared to have a more significant effect in warmer conditions in both species, though constant temperatures were only trialled at a single temperature in this study. Germination was consistently higher at higher temperature regimes, also confirming an adaptation to germination at higher temperatures in these species. Seeds of many species have respond differently to a variety of amplitudes of temperature fluctuation (Thompson \& Grime, 1983). Castellanos-Frias et al. (2014) reported $A$. sterilis germination to be highly adapted to a wide range of temperatures, related to its worldwide distribution. L. rigidum is also reported to be adapted to a broad range of temperatures between 12 and $30^{\circ} \mathrm{C}$ for germination (Turner et al., 2001). The germination responses to temperature of both species are in line with the pattern of winter climate in Saudi Arabia, which can, therefore, be used to predict both the amount and time of seed germination in these species.

However, lower germination rates of both species at some temperatures were found to occur in saline conditions, especially at high concentrations of 300 and $500 \mathrm{mM} / \mathrm{L}$ of $\mathrm{NaCl}$. Results confirmed the sensitivity of both species to water salinity, with low germination at $100 \mathrm{mM} / \mathrm{L}$ of $\mathrm{NaCl}$ and poor to absent germination at higher concentrations. Reduced germination attributed to high salinity has been described by numerous authors (Al-Taisan, 2010). The findings in this study are confirmed by Chauhan et al. (2006), who reported a decrease in germination of $L$. rigidum seeds by $50 \%$ above $40 \mathrm{mM} / \mathrm{L}$ of $\mathrm{NaCl}$ and Watt (1983) who reported low germination of Lolium perenne with increasing salinity in soil or water. Several authors have reported the changes in osmotic potentials caused by $\mathrm{NaCl}$ to be implicated in lower imbibition by seeds and, therefore, lower germination (Almansouri et al., 2001). Welbaum et al. (1990) and Faheed et al. (2005) report generally that salinity stress limits seed germination through osmotic effects. The inhibitory effects of $\mathrm{NaCl}$ on seed germination have been attributed to its direct effect on embryo growth (Al-Taisan,, 2010) and Poljakoff-Mayber et al. (1994) also reported that embryo elongation was strongly inhibited by high levels of $\mathrm{NaCl}$ in irrigation solutions. Seedling growth was inhibited by $\mathrm{NaCl}$ in wheat seedlings germinated in vivo, with development of the coleoptile most affected through a reduction in the rate of respiration with increasing $\mathrm{NaCl}$ concentrations (Moud \& Maghsoudi, 2008).

The ability of both species to resist moderately salty conditions, could reflect their adaptation to a wider range of temperatures. This correlation is supported by Chauhan et al. (2006) who reported some germination of L. rigidum seeds even when watered with a solution at $160 \mathrm{mM} / \mathrm{L}$ of $\mathrm{NaCl}$. A high degree of adaptation in both species to a wide range of temperatures and a degree of water salinity explains their presence in a wide range of natural Saudi climatic conditions. The favoured 
temperatures for the seed germination of both species dominate in Aljouf region northern Saudi Arabia in the winter; $4.2 / 18.6^{\circ} \mathrm{C}$, especially from mid-November to mid-March (Climate report for winter, 2017). Results confirmed that germination of seeds of both species favoured moderate alternating temperatures and showed some resistance to water salinity, which may indicate how both species can be invasive and persistent in arable croplands, and why they are reported as serious weedy species especially in Mediterranean climates and under subtropical conditions. This should be considered in strategies for their control, which should aim to limit the ability of these species to produce large volumes of seeds resulting in large populations.

Acknowledgment: My thank goes to director of Range and Animal Wealth Research and Development Centre in Aljouf Region, Saudi Arabia and his colleagues in the centre for their valuable cooperation in seed collection and shipment. I should like also to thank Mr. Matthew Richardson who is the Senior Technician for workshops \& Controlled Environment at Harborne Building, School of Biological Sciences, University of Reading, UK for allowing me to use the incubators and cold room for the experimental work. My sincere thank goes to my colleague Anas M. Tawfeeq for his help in germination record. This research work did not receive any specific grant from funding agencies in the public, commercial, or not-for-profit sectors.

\section{References}

Almansouri, M., Kinet, J.M. and Lutts, S. (2001) Effect of salt and osmotic stresses on germination in durum wheat (Triticum durum). Plant and Soil, 231, 243-254.

Al-Taisan, W.A. (2010) Comparative effects of drought and salt stress on germination and seedling growth of Pennisetum divisum (Gmel.) Henr. American Journal of Applied Sciences, 7(5), 640-646.

Balyn, R.S., Malik R.K., Panwar, R.S. and Singh, S. (1991) Competitive ability of winter wheat cultivars with wild oats (Avena ludoviciana). Weed Science, 39, 154-158.

Carlson, H.L. and Hill, J.E. (1985) Wild oat (Avena fatua) competition with spring wheat: Plant density effects. Weed Science, 33, 176-181.
Castellanos-Frias, E., Garcia de Leon, D., PujadasSalva, A., Dorado, J. and Gonzalez-Andujar, J.L. (2014) Potential distribution of Avena sterilis in Europe under climate change. Annals of Applied Biology, 165, 53-61.

Chaudhary, S.A. (1989) "Grasses of Saudi Arabia". (Safire Press: Riyadh).

Chauhan, B.S, Gill, G. and Preston, C. (2006) Influence of environmental factors on seed germination and seedling emergence of rigid ryegrass (Lolium rigidum). Weed Science, 54, 1004-1012.

Climate Report for winter (2017) General Authority for Meteorology and Environmental Protection, Saudi Arabia.

Damanakis, M.E. (1983) Weed species in wheat fields in Greece-1982, 1983 survey. Zizaniology, 1, 85-90.

Elghazali, E.B. and Alsoqeer, A.A. (2013) A checklist of the Weed Flora of Qassim Region, Saudi Arabia. Australian Journal of Basic and Applied Sciences, 7(2), 900-905.

Faheed, F.A., Hassanein, A.M. and Azooz, M.M. (2005) Gradual increase in $\mathrm{NaCl}$ concentration overcomes inhibition of seed germination due to salinity stress in Sorghum bicolor L. Acta. Agronomica Hungarica, 53, 229-239.

Gracia Baudin J.M. (1982) Importancia de los 'vallicos' en los cereals de invierno espanoles. Boleitin Del Servicio de Plagas, 8, 179-184.

Jauzein, P. and Montegut, J. (1983) Graminées (Poaceae) nuisibles en agriculture. Versailles: Ecole Nationale Superieure d'Horticulture de Versailles 538p.

Khan, M.A. and Gulzar, S. (2003) Germination responses of Sporoblus ioclados: A saline desert grass. J. Arid Environ., 53, 387-394.

Khan, M.A. and Ungar, I.A. (1999) Seed germination and recovery of Triglochin maritima from salt stress under different thermoperiods. Great Basin Nat. 59(2), 144-150.

Mayer, A.M. and Poljakoff-Mayber, A. (1989) "The Germination of Seeds". $4^{\text {th }}$ ed., Pergamon Press, London. 
Monaghan, N.M. (1980) The biology and control of Lolium rigidum as a weed of wheat. Weed Research, 20, 117-121.

Moud, A.M. and Maghsoudi, K. (2008) Salt stress effects on respiration and growth of germinated seeds of different wheat (Triticum aestivum L) cultivars. World Journal of Agricultural. Sciences, 4(3),351-358.

Ozdener, Y. and Kutbay, H.G. (2008) Effect of salinity and temperature on the germination of Spergularia marina seeds and ameliorating effect of ascorbic and salicylic acids. Journal of Environmental Biology, 29(6), 959-964.

Poljakoff-Mayber, A., Somers, G.G., Werker, E. and Gallagher, J.L. (1994) Seeds of Kosteletzkya virginica (Malvaceae): Their structure, germination and salt tolerance, II. Germination and salt tolerance. American Journal of Botany, 81, 54-59.

Recasens, J., Taberner, A. and Izquierdo, J. (1997) Lolium rigidum Gaud. en cultivos de cereals. In: "Biologia de Las Malas Hierbas de Espana" Sans, X. and Fernandez-Quintanilla, C. (Ed.), pp. 49-64. Phytoma Espana, Valencia, Spain.

Roberts, E.H. (1988) Temperature and seed germination. In: "Plants and Temperature. Symposia of the Society of Experimental Biology", Long, S.P., Woodward, F.L. (Ed.), pp. 42:109-132. Cambridge: Company of Biologists Ltd.

Shannon, M.C. (1998) Adaptation of plants to salinity. Adv. Agron. 60, 75-119.

Thompson, K. and Grime, J.P. (1983) A comparative study of germination responses to diurnallyfluctuating temperatures. Journal of Applied Ecology, 20, 141-156.
Torner, C., Fernandez-Quintanilla, C. and Navarrete, L. (1984) Tolerance and competitive ability of winter cereal cultivars in the presence of Avena sterilis. In Proceedings $3^{\text {rd }}$ EWRS Symposium on Weed Problems in the Mediterranean Area. Oeiras, Portugal, pp.109-115.

Turner, N.C., Thomson, C.J. and Rawson, H.M. (2001) Effect of temperature on germination and early growth of subterranean clover, cape weed and Wimmera ryegrass. Grass and Forage Science, 56, 97-104.

Tutin, T.G., Heywood, V.H., Burges, N.A., Moore, D.M., Valentine, D.H., Walters, S.M. and Webb, D. A. (1980) "Flora Europaea", Vol. 5. Cambridge, UK.

Welbaum G.E., Tissaoui, T. and Bradford, K.J. (1990) Water relations of seed development and germination in muskmelon (Cucumis melo L). III. Sensitivity of germination to water potential and abscisic acid during development. Plant Physiology, 92, 1029-1037.

Watt, T.A. (1983) The effects of salt water and soil type upon the germination, establishment and vegetative growth of Hocus lanatus and Lolium perenne. New Phytologist, 94, 275-291.

Xue, J.G., Wang, X.G., Du, X.G., Mao, P.S., Zhao, L. and Han, J.G. (2012) Influence of salinity and temperature on the germination of Hedysarum scoparium Fisch. Et Mey. African Journal of Biotechnology, 11(14), 3244-3249.

(Received 13/4/2018; accepted 30/ 6/2018 ) 


\title{
انبات بذور الراي الصلب و الثوفان البري في ظروف ملوحة الماء عند درجات الحرارة

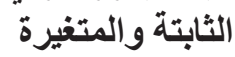

خالا سليمان الشلاش

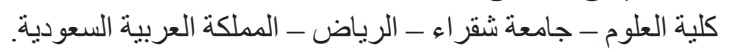

\begin{abstract}
اعشاب الر اي الصلب و الثوفان البري هي اعشاب تتمو في اجز اء مختلفة من العالم سواء في البيئات النباتية



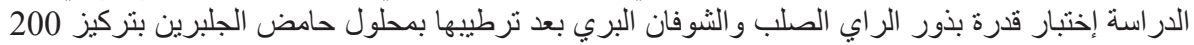

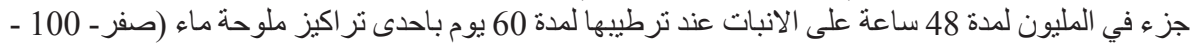

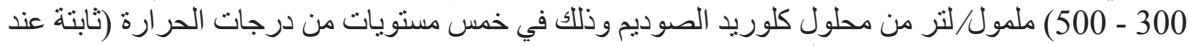


8 ساعات خلال فترة درجة الحرارة الدنياو 16 ساعة إضاءة خلاعة خلال فترة درجة الحر ارة ارة العليا وبنفس النظام 8

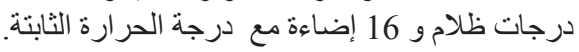

بشكل عام كان إنبات بذور الشوفان أفضل بمستوى معنوية عالية (P>0.001) من بذور الراب في مختلف

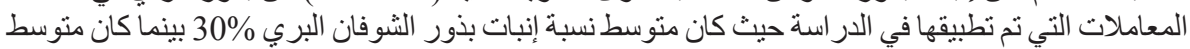







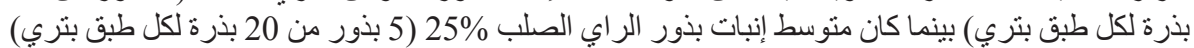

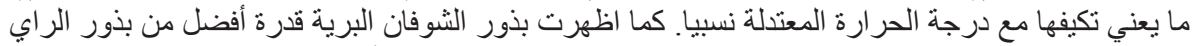

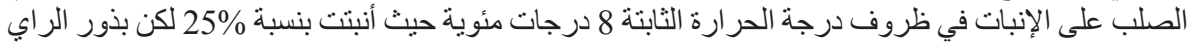

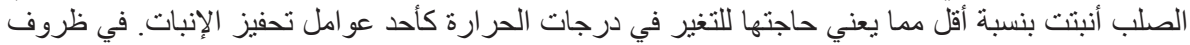

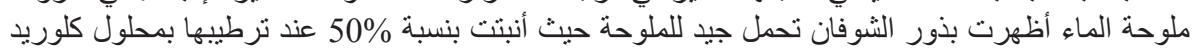

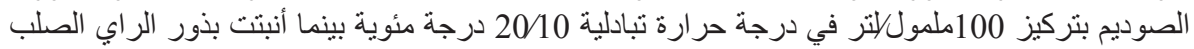



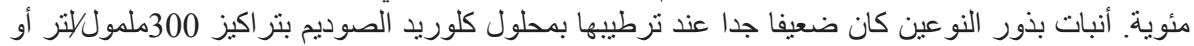

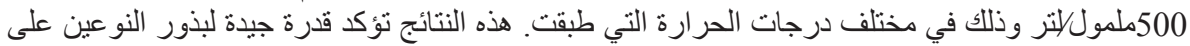

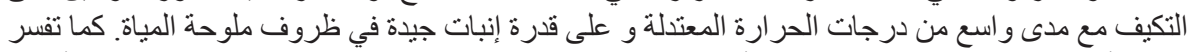

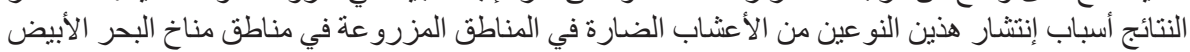

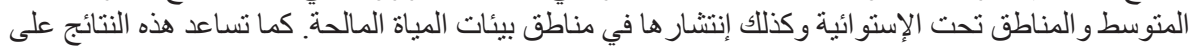



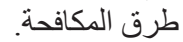

